\title{
Increasing the Competitiveness of Universities and Research Institutions and Their Impact on the Regional Economy Development
}

\author{
Rodnyansky D.V. 1,* Makarov I.N. ${ }^{3,}$ Ovodova A.S., Avtsinova A.A.', Ryazantseva
}

E.A. ${ }^{2}$

\author{
${ }^{1}$ Kazan Federal university, Kazan, 420008, Russia \\ ${ }^{2}$ Razumovsky Moscow state University of technologies and management, Moscow 109004, Russia \\ ${ }^{3}$ Financial University under the Government of the Russian Federation, Lipetsk 398050, Russia \\ *Corresponding author. Email: drodnyansky@gmail.com
}

\begin{abstract}
In this article, the authors examined the relationship between the development of regional and national economies and the level of competitiveness of local scientific and educational institutions and specialists on the example of some regions of the Volga Federal District, namely: the Republic of Mari El, the Republic of Tatarstan, and the Nizhny Novgorod Region. The following research methods were applied: scientific generalization, general scientific methods of logical and comparative analysis, systematization of data, and identification of cause-effect relationships. The analysis showed that in recent years the number of universities has significantly decreased. However, in contrast, there is an increase in scientific organizations involved in innovative developments, as well as an increase in the number of advanced technologies used. Also, the analysis revealed an imbalance in the funding of research: most of the funds belong to the state, while in other countries financing from the business sector predominates. These data allow us to talk about the lack of interaction between business and educational institutions, as well as the fact that it is necessary to change the approach to education in higher educational institutions. The revealed dependencies can be used to justify some recommendations: the need to reduce government interference in the development of scientific and educational institutions; attracting the business sector to participate in innovative developments; increase the scientific activity of students in higher education institutions by involving them in research and further publication in world scientific journals
\end{abstract}

Keywords: education, higher education, regional economy, national economy

\section{INTRODUCTION}

With each new decade, the development of society and its institutions is accelerating. Of course, the main role in this phenomenon is played by the scientific and technological process and innovative development. Education as a resource for promoting an individual in society changes its form and content, but is still one of the key indicators of differentiation of society into "estates". The need for higher education is reduced, there is a tendency towards selfeducation, various courses, professional retraining, training, and online education are gaining popularity . In itself, the form of full-time study and interaction with the teaching staff is becoming less accessible both by time criteria and financial. However, it is thought that it will not completely outlive itself, but will be transformed into much more fundamental knowledge.

The oldest universities in Europe and the USA demonstrate this trend most clearly: they are research centers, the main purpose of which is recognized as the movement of fundamental science towards new discoveries. In Russia, universities are still perceived as an obligatory step towards "successful" employment, and in most of them scientific research is carried out either to a lesser extent, or only by the teaching staff.

Issues related to the development of education in the modern world are relevant and popular among researchers. Much attention is paid to the theme of globalization of modern education and the application of the most successful practices in this area. For example, articles are devoted to this: "Globalization and Internationalization of Higher Education ", Hans de Wit [1]; " Innovation and Good Practices in University Government an d Management ", Francisco Rubio [2]; “Explaining Estimated Economies of Scale and Scope in Higher Educatio n : A Meta-Regression Analysis " [3]; " The Functions and Dysfunctions of 
College Rankings : An Analysis of Institution utional Expenditure " [4].

Another topic of discussion is the degree of state involvement in the educational system. For example, the article " The Effects of State Higher Education Policies and Institutions on Access by Economically Disadvantaged Student s ", Robert C. Lowry [5], examined the possibility of grant support to disadvantaged students for higher education. Other issues of this topic were discussed in the articles: "Mass education or a minority well educated elite in the process of growth: The case of India " [6], "Public education spending and private substitution in urban China " [7] , " Endogenous determination of public budget allocation across education stages " [8] " Socio-economic status and academic performance in higher education : A systematic review" "[9] .

The authors also consider various ways to increase the competitiveness of an educational institution, for example, the article "Internationalization of Higher Education : Theoretical and Empirical Investigation of Its Influence on University Institution Rankings " [10] states that internationalization is one of the important criteria for evaluating a higher educational institution ; and the article " The Impact of US News College Rankings on the Compensation of Colle ge and University Presidents " [11] examined the value of the incentive system for directors of colleges and universities, characterized by payment for the result, and the article " The hidden architecture of higher education : building a big data infrastructure for the ' smarter universit y "'[12] reveals such an important factor for a modern educational institution as digital infrastructure. This article focuses on a major project of an active data infrastructure for higher education in the United Kingdom. It examines the social and technical networks of organizations, programs, standards, dashboards, and visual analytics technologies that make up the infrastructure, and how these technologies merge with government imperatives of market reforms. And the article " The effects of online and blended experience on outcomes in a blended learning environment " [ 13] examines the impact of additional student preparation through online courses on their further education.

A similar theme is reflected in the articles " Network analysis for the study of technological collaboration in spaces for innovation. Science and technology parks and their rela tionship with the university "[14],“ Education's role in China's structural transformation " [15] ," Stakeholders ' role in entrepreneurship education and training programs with impacts on regional development" [16] ," Webinars in higher education and professional training : A meta-analysis and systematic review of randomized controlled trials " [ 17], " The changing world of work in the information age " [ 18] ," From Knowledge Economy to Automation Anxiety: A Growth Regime in Crisis?" [19] . Universities have become a strategic element of the innovation process. Knowledge-based innovations make them key players for the economic and social development of their environment.

The authors are also interested in the question of developing branches of higher educational institutions and what level of knowledge they should give: " The Optimal Global Integration - Local Responsiveness Tradeoff for an International Branch Campus " [20].

\section{METHODOLOGY}

The purpose of this article is to consider the relationship between the development of the regional economy and the level of competitiveness of educational and scientific, institutions and specialists in some regions of the Volga Federal District.

In order to fully consider this relationship, it is necessary to apply the methods of comparative and logical analysis, scientific generalization and the identification of causeeffect relationships.

Universities, NRUs, and other scientific / educational institutions are everywhere faced with a paradigm shift. In the modern world, they have not only the function of transferring knowledge, but also the formation of more and more new technologies, their introduction into practice and the promotion of socio-economic progress. To achieve these goals, educational institutions need to cooperate with business structures and industrial clusters.

Special economic zones designed to generate innovative methods for the production of goods and services are becoming more widespread. The state, in turn, creates preferential conditions for participants in such science and technology parks. The participation of educational and scientific institutions in such projects contributes to competitiveness. And SEZs themselves become key players in the process of obtaining scientific and technical knowledge and in the transfer of technology between universities, research centers and companies.

\section{RESULTS}

This trend demonstrates a direct relationship between the development of regional and national economies and increasing the competitiveness of educational institutions. In this case, a mutually beneficial exchange takes place: the business sponsors scientific and technological research that increases the prestige of the educational institution and, at the same time, provides the business with the necessary qualified personnel, as well as innovative technologies that allow the business to increase profits.

Unfortunately, this mechanism is only beginning to develop in the Russian Federation. This is evidenced by the data presented in the table below. 
Table 1 Structure of internal costs for research and development by sources of financing in $2016, \%$

\begin{tabular}{|c|c|c|c|c|}
\hline & $\begin{array}{c}\text { State } \\
\text { funds }\end{array}$ & $\begin{array}{c}\text { Business sector } \\
\text { funds }\end{array}$ & $\begin{array}{c}\text { Other } \\
\text { national } \\
\text { sources }\end{array}$ & $\begin{array}{c}\text { Foreign } \\
\text { sources }\end{array}$ \\
\hline Russia & 68.2 & 28.1 & 1.0 & 2.7 \\
\hline Kazakhstan & 53.2 & 39.6 & 5.7 & 1.5 \\
\hline Germany & 27.9 & 65.6 & 0.4 & 6.2 \\
\hline Great Britain & 27.7 & 49.0 & 6.3 & 17.1 \\
\hline Poland & 41.3 & 39.0 & 2.4 & 6.7 \\
\hline China & 20.0 & 76.1 & 3.2 & 0.7 \\
\hline Singapore & 37.1 & 54.1 & 2.0 & 6.8 \\
\hline Japan & 15.0 & 78.1 & 6.2 & 0.7 \\
\hline USA & 25.1 & 62.3 & 7.4 & 5.2 \\
\hline Australia & 34.6 & 61.9 & 1.9 & 1.6 \\
\hline
\end{tabular}

According to the table, it is clear that state funding for research and development prevails in the Russian Federation, it accounts for $68.2 \%$ of total costs and this is more than 2 times higher than financing by the business sector. Compared to Russia, in the most developed countries the share of entrepreneurs 'funds exceeds the funds of the public sector: Japan shows the largest share of $78.1 \%$. But even in those countries where, as in Russia, public sector funds prevail in the structure of research and development costs, their share is still less: in Kazakhstan $53.2 \%$, in Poland $-41.3 \%$. Moreover, in the international ranking of educational institutions, universities in Germany, England, China, Singapore, Japan, the United States are more common than Russian. Also, these countries are leaders in innovative development and demonstrate stable growth of the national economy.

Another change that the modern economy is facing, and which does not bypass the education sector, is a shift in emphasis from quantity to quality. Society has long passed from extensive methods of development to intensive, but with the fourth industrial revolution and the advent of the Internet, this became most pronounced. Many have ceased to need higher education, because everyone can get the necessary competencies in the online space much faster and cheaper. This fact, on the one hand, affects the reduction in the number of educational institutions, since they simply do not recruit the required number of students, but on the other hand increase the quality and prestige of full-time education. After all, this stimulates higher education institutions to adapt curricula to the current context, to attract faculty of a high professional level, to organize international interaction between universities, the globalization of education, and cooperation with businesses interested in personnel with certain competencies. Since 2010 , there has been a tendency to reduce the number of educational organizations, which confirms the above points.

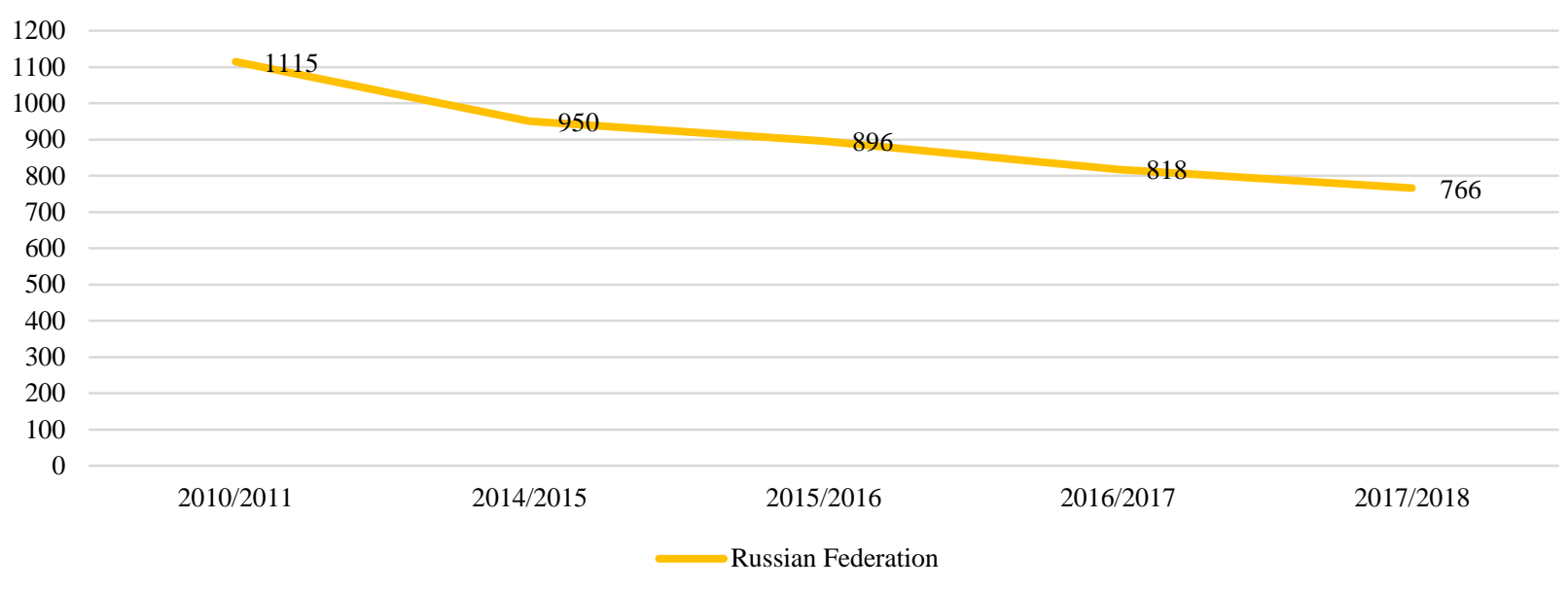

Figure 1 The number of educational institutions of higher education and scientific organizations 
We also would like to note the trend of budget spending shifting towards the development of education in the studied regions. Here are some figures. increase in the number of scientific studies conducted. Which, in turn, led to an increase in the developed advanced technologies. Below are the statistics for the studied regions.

This graph shows an increase in the number of organizations performing research and development; the constructed trend line suggests further positive dynamics.

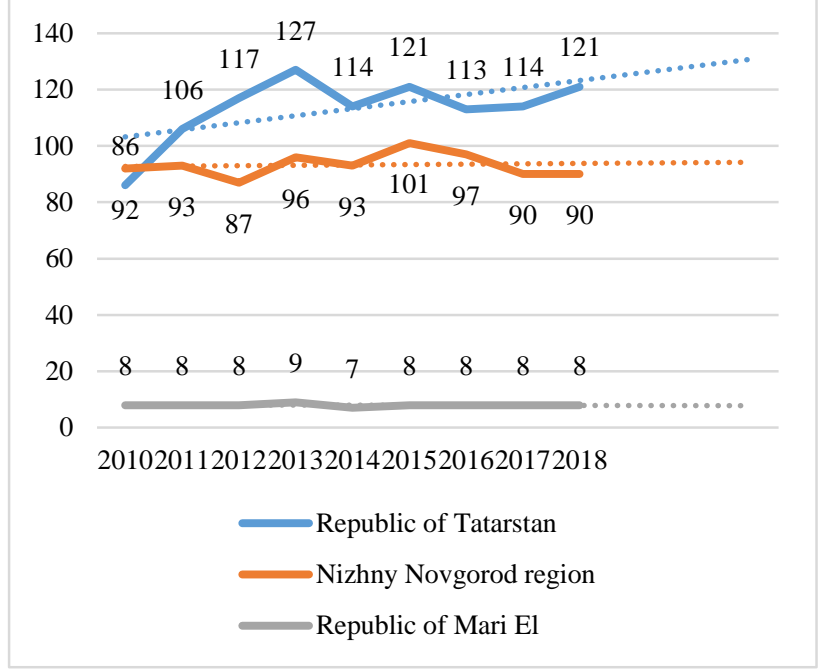

Figure 2 The number of educational organizations performing research and development

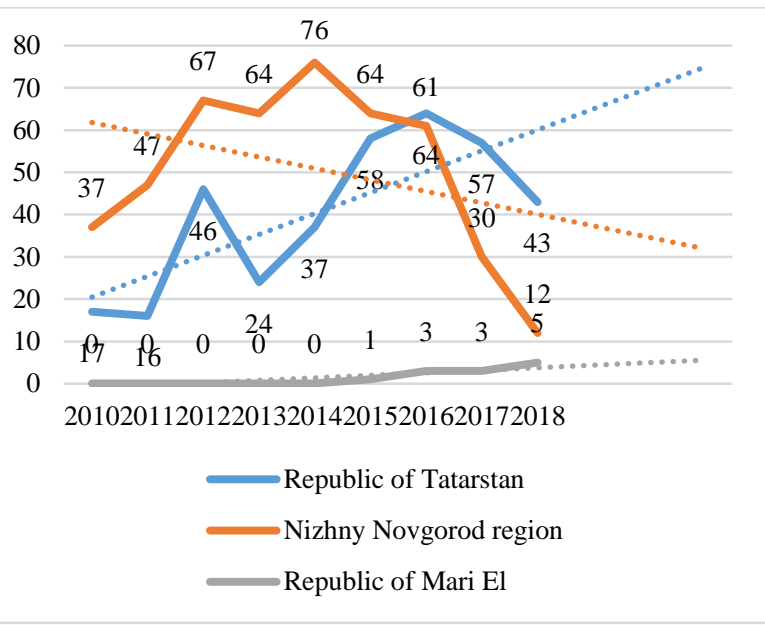

Figure 3 Number of advanced manufacturing technologies developed

Despite the fact that in the second figure we observe a decline in the number of advanced technologies after 2016 in two regions - the Republic of Tatarstan and the Nizhny Novgorod Region, in general, the development dynamics of this indicator is positive. The data of the presented graphs indirectly confirm the existence of cooperation between the participants of the economic market - enterprises, innovative business and scientific, research, educational institutions in these regions.
Republic of Tatarstan

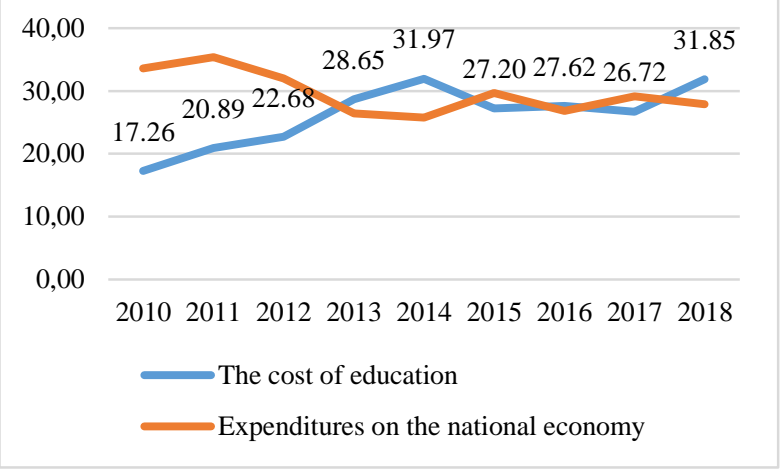

Figure 4 Shares of expenses on education and the national economy of the total expenses of the consolidated budget of the subject

This graph shows the change in the share of expenses of the consolidated budget of the Republic of Tatarstan from 2010 to 2018. As you can see, at the beginning of this period, the share of education spending was significantly lower than the cost of the national economy, but by 2018 the situation has changed - now the share of education spending is $31.85 \%$ compared to $27.92 \%$ of the cost of the national economy.

\section{Nizhny Novgorod region}

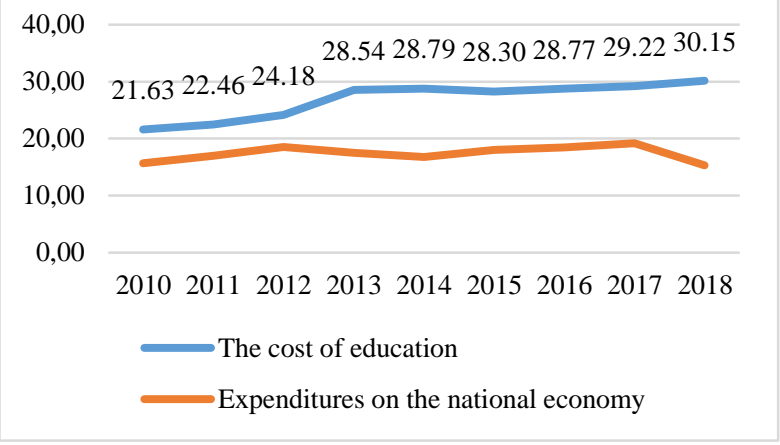

Figure 5 Shares of expenses on education and the national economy of the total expenses of the consolidated budget of the subject

A similar graph reflects the situation in the Nizhny Novgorod region. And here we see the predominance of spending on education throughout the studied time period. Also, by 2018 , there is an even larger gap - $30.15 \%$ is spent on education and only $15.34 \%$ on the national economy. 


\section{Republic of Mari El}

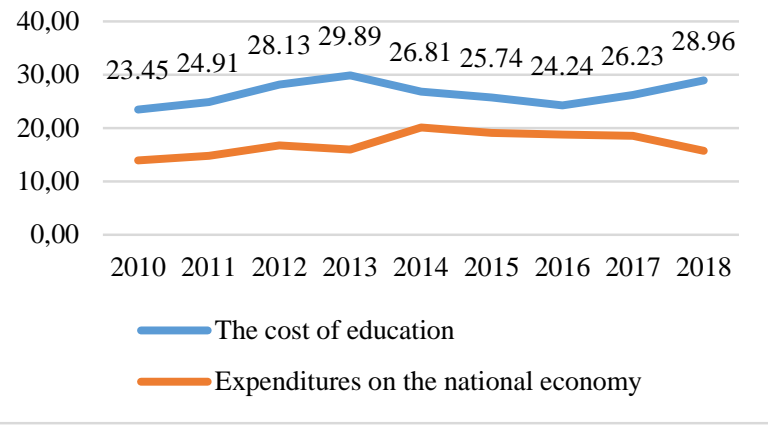

Figure 6 Shares of expenses on education and the national economy of the total expenses of the consolidated budget of the subject

Well, in the last studied region, the Republic of Mari El, there is also a tendency towards an increase in the share of expenses on education, which undoubtedly affected the number of innovative developments used in practice presented above .

Despite the development of interaction between economic participants and scientific, educational institutions, it is important to understand that it will take time and resources to reach the proper level. For completeness, it is necessary to compare the development of innovative activity in Russia with other countries. This comparison is presented in the diagram below.

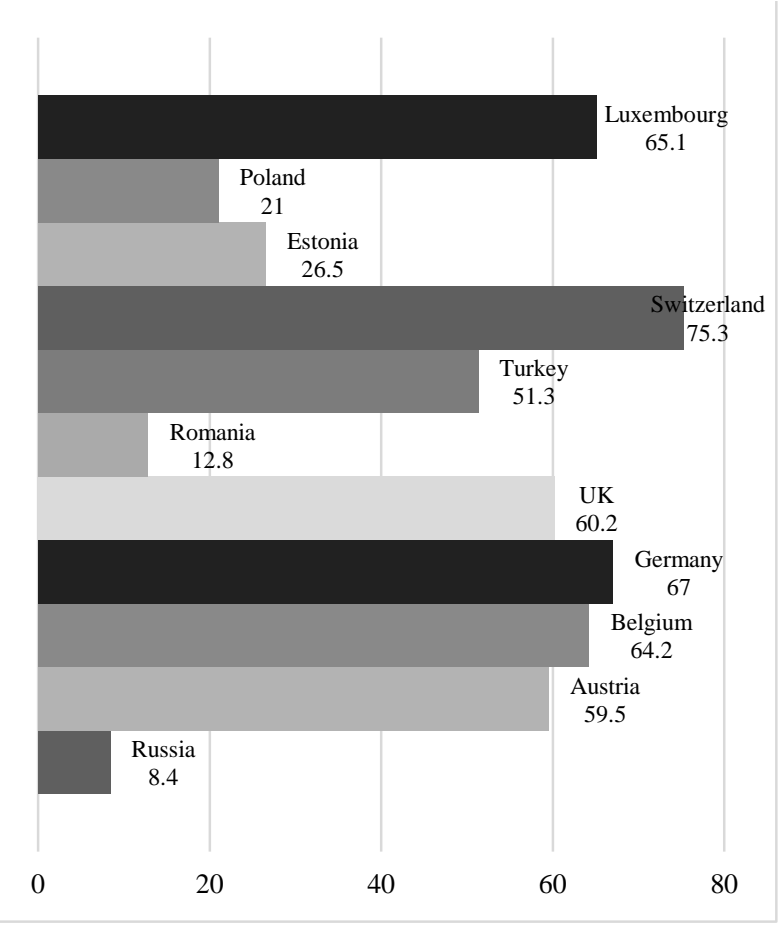

Figure 7 The total level of innovative activity of organizations in 2016
It can be seen from the diagram data that the share of innovation- active organizations in Russia is several times less than the corresponding indicator in many European countries. Pay attention to Luxembourg - a country whose population is 285 times less than the population of Russia, and the area - 6,603 times, and nevertheless, the proportion of organizations using innovative developments in it is $65.1 \%$. This suggests that Russia, which has enormous resources, both human and material, will still have to learn to use them rationally.

The next step would be to consider Russia's participation in the global scientific community by the example of the number of publications in scientific journals indexed in Web of Science. Below is a chart showing the share of countries in the total number of publications.

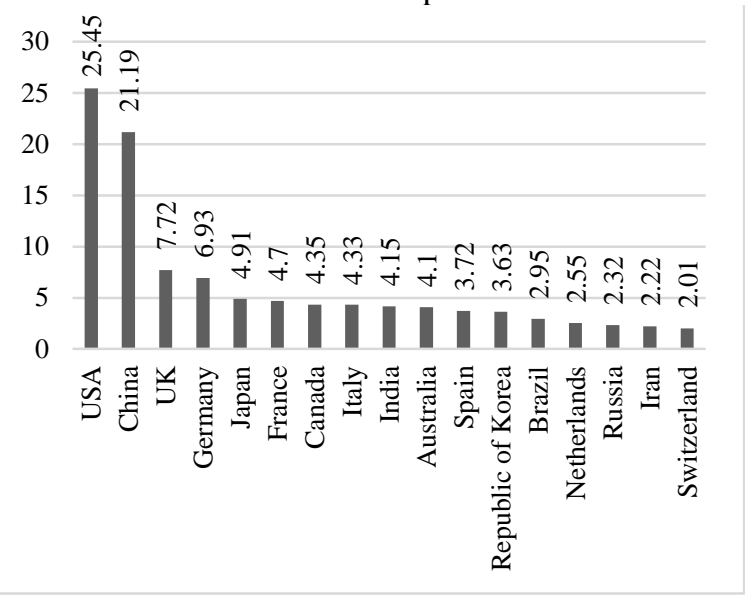

Figure 8 The share of countries in the total number of publications in scientific journals indexed in Web of Science, 2017, \%

The specific gravity of Russia is $2.32 \%$. Confident leaders are the United States and China. We believe that one of the priorities for the development of scientific and educational institutions may be getting into the top 10 of the presented list.

\section{DISCUSSIONS}

Based on all the data obtained, conclusions can be drawn about the development of the competitiveness of scientific and educational institutions in the studied regions and their interaction with the regional and national economies:

- the number of scientific and educational institutions has significantly decreased since 2010 , which may indicate bad development trends on the one hand, but, in modern society, it can be interpreted as improving the quality of education, due to an increase in their level of competitiveness;

- special economic zones are developing rapidly in the national economy of Russia, which can become key players in the process of obtaining scientific and technical knowledge and in the transfer of technology between universities, research centers and companies; 
- the regions under study demonstrate a shift in spending priorities towards education;

- there is a positive trend in the development of organizations involved in scientific and innovative developments;

- state funding for research and development prevails;

- today, the Russian Federation is lagging behind in the number of innovatively active organizations.

An assessment of the development of the competitiveness of scientific and educational institutions in the studied regions and their interaction with the regional and national economies revealed important growth areas: the need to enter the top 10 countries with the largest share of publications in scientific journals indexed in Web of Science, the need to develop digital infrastructure.

Based on the analysis and foreign experience, the following recommendations can be proposed:

- reduction of state interference in the development of scientific and educational institutions;

- attracting the business sector to participate in innovative developments, including financial;

- increasing the scientific activity of students in higher educational institutions, attracting them to conduct research and further publication in world scientific journals;

- a change in the paradigm of education from "compulsory for a tick" to "a unique resource for the development and formation of the personality as a competent employee".

\section{CONCLUSION}

In this article, the authors discovered and statistically confirmed important hypotheses: the development of regional and national economies directly affects scientific and educational activity, since this increases the amount of material resources poured into the environment. However, state funds still prevail in financing educational and scientific institutions, while world experience shows the effectiveness of the interaction of these institutions with the business sector. It is also confirmed by international experience that in order to increase the competitiveness of educational and scientific institutions, it is necessary to create a digital infrastructure, and also not to impede the globalization and internationalization of education.

This study provides an opportunity to assess the prospects for the development of competitiveness of scientific and educational institutions in the Russian Federation, and also formulates the main problems that require increased attention.

The novelty of the author's proposals is that the issue of reducing the number of educational and scientific institutions has so far been considered a problem. However, the presented dynamics of the development of innovative developments shows that the quality of education and science is more important than the number of universities. Therefore, the introduction of additional incentives for students' scientific activities is a necessary approach for the development of competitiveness of local educational and scientific institutions.
Improving the competitiveness of educational and scientific institutions is an important priority for the development of the state. Indeed, as shown by the data analyzed in this article, the regional and national economies draw from the sphere of education unique resources - people with the necessary competencies and innovative, advanced technologies that can bring entrepreneurship to a new level. As a comparative analysis with other countries has shown, Russia has zones that are still lagging behind, but without a doubt, that have enormous potential to develop. It seems that the right course has been chosen now, the main thing is to understand that the ultimate goal is the development of the state as a whole. And it is not possible without a balanced system in which everything has the same weight: education, business, and government policy.

\section{REFERENCES}

[1] H.Wit, Globalisation and Internationalisation of Higher Education», J. of Educational Technology in Higher Education, 8 (2011) 241-248

[2] F. Rubio, Innovation and Good Practices in University Government and Management, Int. Journal of Educational Technology in Higher Education, 9 (2012) 261-266

[3] L.C. Zhang, A.C. Worthington, Explaining Estimated Economies of Scale and Scope in Higher Education: A Meta-Regression Analysis, Research in Higher Education, 59 (2018) 156-173

[4] J. Kim, The Functions and Dysfunctions of College Rankings: An Analysis of Institutional Expenditure, Research in Higher Education, 59 (2018) 54-87

[5] R. C. Lowry, The Effects of State Higher Education Policies and Institutions on Access by Economically Disadvantaged Students, Research in Higher Education, 60(2019) 44-63

[6] A. Castelló-Climenta, A.Mukhopadhyayb, Mass education or a minority well educated elite in the process of growth: The case of India, J. of Development Economics, 105 (2013) 303-320

[7] C. Yuana, L. Zhangb, Public education spending and private substitution in urban China, J. of Development Econ., 115 (2015) 124-139

[8] X. Su, Endogenous determination of public budget allocation across education stages, J. of Development Economics, vol. 81-2 (2006) 438-456

[9] C. F. Rodríguez-Hernándeza, E. Cascallara, E.Kyndtbc, Socio-economic status and academic 
performance in higher education: A systematic review, Educational Research Review, vol. 29 (2020)

[10] B.L. Delgado-Márquez, N.E. Hurtado-Torres, Ya. Bondar, Internationalization of Higher Education: Theoretical and Empirical Investigation of Its Influence on University Institution Rankings, Int. J. of Educational Technology in Higher Education, vol. 8 (2011) 265-284

[11] R. Yeung, P. Gigliotti, P. Nguyen-Hoang, The Impact of U.S. News College Rankings on the Compensation of College and University Presidents, Research in Higher Education, vol. 60 (2019) 1-17

[12] B.Williamson, The hidden architecture of higher education: building a big data infrastructure for the 'smarter university', Int. J. of Educational Technology in Higher Education, vol.15 (2018) 12

[13] C.J.Asartaa, J.R.Schmidt, The effects of online and blended experience on outcomes in a blended learning environment, The Internet and Higher Education, vol. 44 (2020)

[14] M. Farré-Perdiguer, M. Sala-Rios, T. TorresSolé, Network analysis for the study of technological collaboration in spaces for innovation. Science and technology parks and their relationship with the university, Int. J. of Educational Technology in Higher Education, vol. 13 (2016) 8

[15] S. Leea, B. A.Malin, Education's role in China's structural transformation, J.of Development Economics, vol. 101 (2013) 148-166

[16] A.R. Galvãoac ,C.S.E. Marquesa, J. J.Ferreirab, V. Bragac, Stakeholders' role in entrepreneurship education and training programmes with impacts on regional development, J. of Rural Studies, 24 (2020)

[17] A.Gegenfurtnerab, C. Ebnerb, Webinars in higher education and professional training: A meta-analysis and systematic review of randomized controlled trials, Educ. Research Review, 28 (2019)

[18] M. Carnoy, The changing world of work in the information age, J. New Political Econ., vol. 3 (2007) $123-128$ 